\title{
Ground subsidence and heave over permafrost: hourly time series reveal interannual, seasonal and shorter-term movement caused by freezing, thawing and water movement
}

\author{
Stephan Gruber \\ Department of Geography and Environmental Studies, Carleton University, Ottawa, ON, K1S 5B6, Canada \\ Correspondence: Stephan Gruber (stephan.gruber@ carleton.ca)
}

Received: 29 September 2019 - Discussion started: 1 October 2019

Revised: 22 March 2020 - Accepted: 1 April 2020 - Published: 30 April 2020

\begin{abstract}
Heave and subsidence of the ground surface can offer insight into processes of heat and mass transfer in freezing and thawing soils. Additionally, subsidence is an important metric for monitoring and understanding the transformation of permafrost landscapes under climate change. Corresponding ground observations, however, are sparse and episodic. A simple tilt-arm apparatus with logging inclinometer has been developed to measure heave and subsidence of the ground surface with hourly resolution and millimeter accuracy. This contribution reports data from the first two winters and the first full summer, measured at three sites with contrasting organic and frost-susceptible soils in warm permafrost. The patterns of surface movement differ significantly between sites and from a prediction based on the Stefan equation and observed ground temperature. The data are rich in features of heave and subsidence that are several days to several weeks long and that may help elucidate processes in the ground. For example, late-winter heave followed by thawing and subsidence, as reported in earlier literature and hypothesized to be caused by infiltration and refreezing of water into permeable frozen ground, has been detected. An early-winter peak in heave, followed by brief subsidence, is discernible in a previous publication but so far has not been interpreted. An effect of precipitation on changes in surface elevation can be inferred with confidence. These results highlight the potential of ground-based observation of subsidence and heave as an enabler of progress in process understanding, modeling and interpretation of remotely sensed data.
\end{abstract}

\section{Introduction}

The presence, formation and decay of ground ice control many phenomena in cold regions. Especially at locations with permafrost, large amounts of ground ice can exist and its decay may have pronounced effects at the terrain surface (Shumskiy and Vtyurin, 1963; Mackay, 1970; Heginbottom, 1973). In recent decades, the interest in observation (Liu et al., 2010; Bartsch et al., 2019) and prediction (Hwang, 1976; Lee et al., 2014) of ground subsidence has been increasing along with the prevalence of ground-ice loss due to anthropogenic climate change.

The formation and melt of excess ice, the volume of ice in the ground exceeding the total pore volume under natural unfrozen conditions, is an expression of the redistribution of mass and energy and often a major determinant of surface heave and subsidence in response to freezing and thawing of soil. Excess ice forms through a number of processes (Outcalt, 1971; Rempel et al., 2004), and when it melts, the soil consolidates (Nixon et al., 1971). These phenomena are superimposed on the volume changes without redistribution of mass, which are due to thermal expansion of soil materials and the density contrast of water and ice. Together, these processes define the thermo-hydro-mechanical behavior of the active layer and permafrost. Challenging the simple distinction of active layer and permafrost (Shur et al., 2005), the existence of a transition zone points to the importance of its thermo-hydro-mechanical dynamics for linking surface deformation, phenomena of thawing and freezing, and climate change. As a consequence, the analysis and simulation of subsidence due to permafrost thaw may require careful attention not only to the loss of excess ground ice, but also 
to the dynamics of its episodic growth. While time series of ground temperature are widely available but rare for moisture content, they are nearly nonexistent for surface heave and subsidence.

Most in situ and remote observations of surface displacement have frequencies ranging from a few times per year to multiannual. A common assumption in the interpretation of such data is that a seasonal signal is superimposed on, and can be distinguished from, the longer-term trend. When only decadal-scale change is of interest and clearly dominates in the observations available, seasonal or higher-frequency signals may be ignored in data interpretation (e.g., O'Neill et al., 2019; Streletskiy et al., 2017). If, however, their magnitudes are similar or only short time series are available (cf. Anonymous, 1969), the shape of the seasonal cycle and its adequate sampling become important during interpretation. The most common assumption is that the seasonal progression of subsidence or heave resembles the square root of accumulated thawing or freezing degree days, as predicted by the Stefan equation (e.g., Liu et al., 2010; Bartsch et al., 2019). The validity of this assumption, however, is rarely tested and likely differs between locations and years.

High-resolution data on ground heave and subsidence can support improved understanding and modeling of the underlying processes and phenomena. They can complement temperature monitoring with time series of inferred groundice loss or aggradation, an important element of the subsurface energy balance and ground thermal regime that is often neglected in observations. Finally, high-resolution data can provide ground truth for other methods of sensing surface subsidence. The potential of high-resolution measurements of surface displacement has been demonstrated for environments with permafrost and with only seasonally frozen soil (e.g., Overduin and Kane, 2006; Harris et al., 2008). These studies measured hourly surface displacement with millimeter accuracy and revealed subseasonal fluctuations as well as differences in seasonal patterns between years. As they require sturdy support frames and elaborate data logging systems, however, such installations are expensive to deploy and maintain.

Better understanding the dynamics of surface displacement in response to freeze-thaw processes superimposed on the potential of net subsidence requires methods that can be applied at many locations and in the long term. This study demonstrates a robust and relatively inexpensive candidate method for measuring the vertical movement of natural soil surfaces of about $30 \mathrm{~cm} \times 30 \mathrm{~cm}$ with hourly to daily temporal resolution and millimeter accuracy. This contribution has three objectives: (1) to describe the tilt-arm method in terms of its design and expected accuracy, and to share lessons learned from its initial deployment; (2) to describe and interpret the features visible in tilt-arm data - as heave and subsidence are driven by meteorological forcing but also modulated by site conditions, the commonalities and contrasts between sites of varying similarity will be examined; and (3) to test the hypothesis that seasonal vertical ground movement is well approximated by the Stefan model.

\section{Background: measuring subsidence and heave}

\subsection{Episodic observation}

Methods for observing heave and subsidence at point locations in situ and areally by remote sensing are discussed in a recent review (Arenson et al., 2016). Here, the characteristics of in situ methods are presented to provide context for the new method proposed. Elevation change of the soil surface, or for differing depths beneath the surface when telescoping aluminum tubes are used, has been measured relative to metal or fiberglass rods anchored in permafrost (e.g., Mackay et al., 1979; Smith, 1985, 1987; Overduin and Kane, 2006; O'Neill and Burn, 2012). The accuracies reported are $\pm 1-5 \mathrm{~mm}$, and the frequency of manual readings ranges from once every several years to more than 10 times per year.

Maximum heave and subsidence, over typically 1 year, can be recorded with heave sleeves (Nixon et al., 1995) that has a typical accuracy of $\pm 10 \mathrm{~mm}$ (Nixon and Taylor, 1998). These comprise a small section of metal tubing connected to a grille resting on the ground surface. As the sleeve moves up and down a reference pipe anchored in permafrost, a protrusion scratches a painted section on it. Heave sleeves are robust and highly efficient for recording long-term change (O'Neill et al., 2019). Optical leveling of markers against benchmarks has reported accuracies on the order of \pm 1 20 mm (e.g., Mackay et al., 1979; Mackay, 1973). Differential GNSS (Global Navigation Satellite System) surveying has reported accuracies of $\pm 9-40 \mathrm{~mm}$ (e.g., Little et al., 2003; Lambiel and Delaloye, 2004; Streletskiy et al., 2017).

\subsection{Automatic observation}

Analogue recorders (Matthews, 1967; Fahey, 1974) and later electronic data loggers with displacement transducers (Matsuoka, 1994, 2003; Matsuoka et al., 1997; Hallet, 1998; Harris et al., 2007, 2008; Matsumoto et al., 2010) have been used to measure surface elevation relative to deeply anchored metal frames at hourly intervals. The accuracies reported are on the order of $\pm 1 \mathrm{~mm}$. In a similar mode of installation, ultrasonic distance sensors, although affected by the presence of snow and vegetation, have been used to record hourly surface movement with an accuracy of about $\pm 10 \mathrm{~mm}$ (Overduin and Kane, 2006).

In steep unconsolidated materials, subsidence has been revealed from a combination of continuous GNSS and inclinometer observations (Wirz et al., 2014, 2016a, b) and in bedrock with a combination of multiple crack meters (Hasler et al., 2012; Weber et al., 2019), where ice loss has also been inferred from ambient seismic vibration (Weber et al., 2018). 
Table 1. Sites details, including coordinates (west, north), serial numbers of instruments, active layer thickness (ALT) and the approximate thickness of the organic layer overlying mineral soil.

\begin{tabular}{llrrr}
\hline Site name & Coordinates & Serial & ALT & Organic \\
\hline Evil Peat & $114.016,62.554$ & 5120 & $1.2 \mathrm{~m}$ & $1.5 \mathrm{~m}$ \\
Drill the Chill & $114.532,62.457$ & 5121 & $0.7 \mathrm{~m}$ & $1.1 \mathrm{~m}$ \\
Active Slayer & $114.095,62.540$ & 5122 & $1.3 \mathrm{~m}$ & $0.1 \mathrm{~m}$ \\
\hline
\end{tabular}

\section{Study area and sites}

The sites instrumented are within $25 \mathrm{~km}$ from Yellowknife, Northwest Territories, Canada. Climate is continental subarctic with a mean annual air temperature of $-3.6^{\circ} \mathrm{C}$ and an average annual precipitation sum of $291 \mathrm{~mm}$ observed at the airport (YZF) during 1971-2000. The maximum mean monthly snow depth of $0.39 \mathrm{~m}$ is usually reached in February. Permafrost near Yellowknife exists mostly in black spruce forests underlain by fine-grained frost-susceptible soils and in open black spruce forest peatlands (Morse et al., 2016). Active layer thicknesses were $0.6-1.2 \mathrm{~m}$ at mineral soil sites and $0.5-0.7 \mathrm{~m}$ in peatlands.

Three sites were instrumented (Table 1) on 6-8 July 2017. Drill the Chill is in a peatland with open black spruce and tamarack forest, $8 \mathrm{~km}$ west of Yellowknife. The organic layer has a thickness of about $1.1 \mathrm{~m}$ and is underlain by reworked glaciolacustrine silt; the active layer is about $0.7 \mathrm{~m}$ thick. Evil Peat is in a peatland with open black spruce and tamarack forest, $21 \mathrm{~km}$ northeast of Yellowknife. The organic layer has a thickness of about $1.5 \mathrm{~m}$, followed by an interval of fluvial sand with a thickness of $0.35 \mathrm{~m}$ and glaciolacustrine silt below. The active layer is about $1.2 \mathrm{~m}$ thick. Active Slayer is located in dense black spruce forest $17 \mathrm{~km}$ northeast of Yellowknife, with about $0.1 \mathrm{~m}$ of organics overlying hummocks in mineral soil. The active layer is about $1.3 \mathrm{~m}$ thick beneath hummock tops.

\section{Materials and methods}

\subsection{Tilt arm}

The vertical movement of the soil surface is measured via the changing inclination of a tilting arm that connects a reference point with a small grille buried just beneath the vegetation mat at a distance of $1.5 \mathrm{~m}$ (Fig. 2). The tilt arm was constructed from hard wood (aged red oak) to have minimal thermal expansion and coated with urethane varnish for waterproofing. The reference point is given by a pivot attached to pipe anchored in permafrost at depth. When tilting, the changing horizontal distance between the anchor pipe and the ground attachment is accommodated by a double-pivot mechanism. This design minimizes the disturbance of the surface and subsurface at the point measured. It has few mov- ing parts, is simple to build, and is suitable for anchoring on borehole casing pipes used for thermal monitoring or as benchmarks. The red dots visible on top of the anchor point (Fig. 2b) and the soil attachment (Fig. 2c) facilitate surveying or optical leveling to relate the installation to external benchmarks. This may help to detect if the anchor pole was frost jacked.

A metal pipe with a length of about three meters was installed at each site to provide anchoring in permafrost at depth. After inserting the pipes, the holes were filled with coarse sand to avoid heaving phenomena during refreezing. At a distance of $10 \mathrm{~m}$ or less from the tilt arms, soil temperature has been logged $0.30-0.35 \mathrm{~m}$ deep. The digital sensors are accurate to $\pm 0.1^{\circ} \mathrm{C}$ and measure hourly. Daily total precipitation and snow height are available for the Yellowknife airport (Government of Canada, 2019).

A tilt logger, RST model IC6560, with a microelectromechanical system (MEMS) accelerometer and $4 \mathrm{MB}$ of memory is used to record hourly time series of inclination. It measures one axis with a range of $\pm 15^{\circ}$ and has an operating range of -40 to $60^{\circ} \mathrm{C}$. The instrument has a resolution of $\pm 0.0006^{\circ}$ and a repeatability of $\pm 0.002^{\circ}$ as stated by the manufacturer. When applied to a near-horizontal tilt arm of $1.5 \mathrm{~m}$ this is equivalent to resolving elevation differences of $\pm 0.015 \mathrm{~mm}$ with a repeatability of $\pm 0.045 \mathrm{~mm}$. When mounted on the tilt arm, positive inclination corresponds to lowering of the end embedded in the soil.

\subsection{Conversion from inclination to elevation difference}

Measured inclination is converted to elevation change based on the geometry of the tilt arm (Fig. 3) with $L=1.5 \mathrm{~m}$ and $P=0.115 \mathrm{~m}$. The vertical distance of the arm's end from the reference point is $\mathrm{d} Y_{L}=\sin (\alpha) \times L$, based on the angle $\alpha$ $\left.{ }^{\circ}\right)$ between the horizontal plane and the inclined arm with length $L$. The changing horizontal distance during tilting is $\mathrm{d} X=(1-\cos (\alpha)) \times L$. The vertical distance between the arm's end and the ground attachment, added by the doublepivot mechanisms with length $P$, is $\mathrm{d} Y_{P}=\sqrt{P^{2}-\mathrm{d} X^{2}}$ using the Pythagorean theorem. The vertical distance between the reference point and the ground attachment can then be calculated as $\mathrm{d} Y=\mathrm{d} Y_{L}+\mathrm{d} Y_{P}$ or

$\mathrm{d} Y=\sin (\alpha) L+\sqrt{P^{2}-(1-\cos (\alpha))^{2} L^{2}}$.

\subsection{Error from thermal expansion and contraction}

The vertical error introduced by thermal expansion of the anchor pipe is $\varepsilon_{\mathrm{AP}}=\mathrm{d} T \beta A$, with $\mathrm{d} T\left({ }^{\circ} \mathrm{C}\right)$ being the temperature difference causing expansion, $\beta\left(\mathrm{m}(\mathrm{m} \mathrm{K})^{-1}\right)$ the coefficient of linear thermal expansion, and $A(\mathrm{~m})$ the length of the anchor pipe between the permafrost and the elevation of the tilt-arm reference point. As permafrost becomes nearisothermal and soft, the actual anchoring point may be deeper 


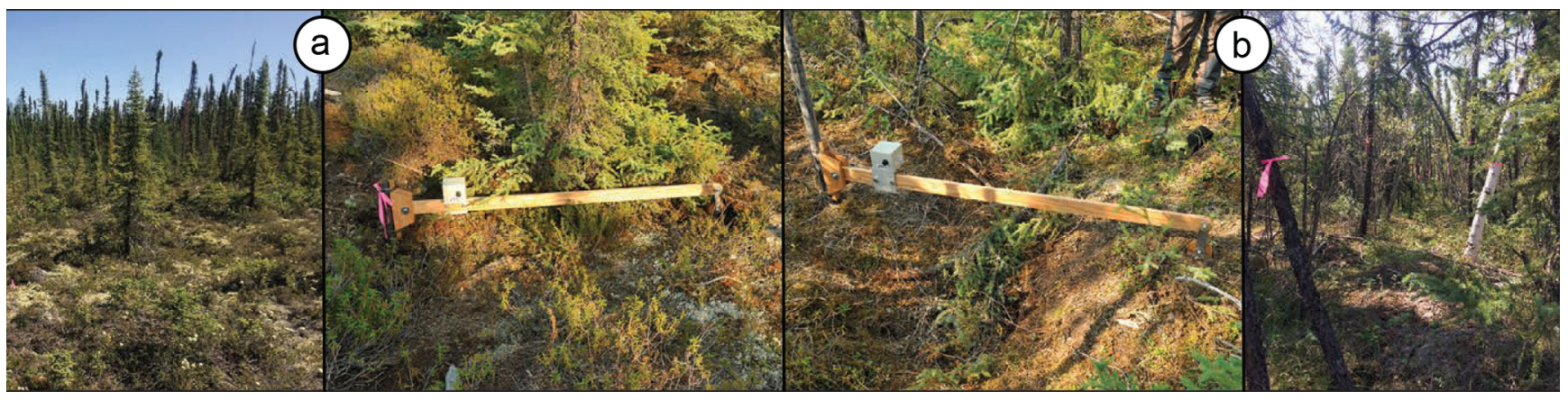

Figure 1. Overview images and close-up photographs of ground cover around tilt arms showing the character of the sites instrumented. Site Evil Peat (a), similar to site Drill the Chill, is in a peatland with open black spruce and tamarack forest. Site Active Slayer (b) is in dense black spruce forest overlying hummocks in mineral soil.

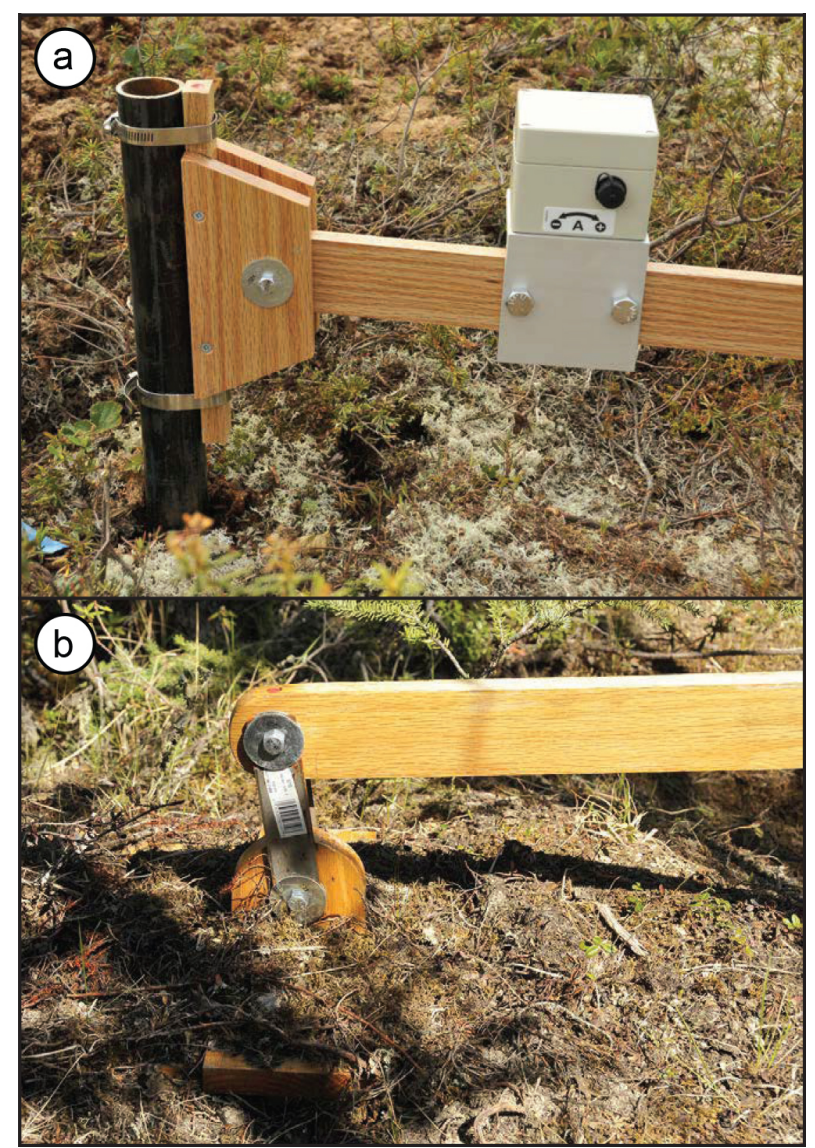

Figure 2. Detailed views on the tilt-arm logger and the attachment to the anchor pipe (a) and the double-pivot mechanism (b) just above the wooden grille inserted beneath the vegetation. See Fig. 1 for an overview image of tilt arms.

than the permafrost table. While this may be a problem for the anchoring of the pipe, temperature fluctuations will be subdued. To generate an extreme (high) estimate of $\varepsilon_{\mathrm{AP}}$, let the active layer be $1.2 \mathrm{~m}$ thick and entirely at the shallow soil temperature measured, and let the length of anchor pipe ex-

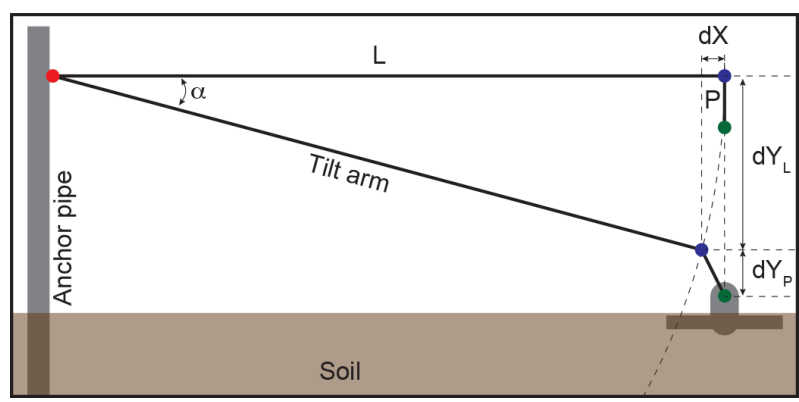

Figure 3. Geometry of the tilt arm defined by the lengths of the arm $(L)$ and the double-pivot mechanism $(P)$. The reference point on the anchor pipe is shown in red, the end of the tilt arm in blue and the ground attachment at the end of the double pivot in green. Only vertical soil movement is measured.

posed above the ground surface be $0.5 \mathrm{~m}$ and at the temperature measured inside the tilt logger. The temperature-related vertical error introduced by the tilt arm is approximated as $\varepsilon_{\mathrm{TA}}=\mathrm{d} Y-\mathrm{d} Y(T)$ based on Eq. (1), where $\mathrm{d} Y(T)$ denotes the temperature-affected vertical distance obtained from using the thermally expanded lengths for the tilt $\operatorname{arm} L(T)$ and double pivot $P(T)$. As $\varepsilon_{\mathrm{TA}} \propto \alpha$, only values for $\alpha=15^{\circ}$ are reported; the tilt arm is assumed to be at the temperature measured by the logger. The maximum ranges of instantaneous temperatures in soil $\left(41^{\circ} \mathrm{C}\right)$ and in the logger $\left(85^{\circ} \mathrm{C}\right)$ were measured at Active Slayer, and for these, estimated errors for typical materials are listed in Table 2. The assumptions on temperature fluctuation and angles are extreme and represent a deliberately high estimate of error induced by thermal expansion of the measurement setup. Even so, the combined error from tilt arm and anchor pipe is $\pm 0.6 \mathrm{~mm}$ and, therefore, neglected in the results presented.

\subsection{Error from temperature stability of tilt meter}

Laboratory testing was performed to investigate temperaturerelated artifacts in the inclination recorded. Instruments were 
Table 2. Estimated maximum error resulting from thermal expansion of anchor pipe $\varepsilon_{\mathrm{AP}}(\mathrm{mm})$ and tilt arm $\varepsilon_{\mathrm{TA}}(\mathrm{mm})$ for common materials, together with typical values of the coefficient of linear thermal expansion $\beta\left(10^{-6} \mathrm{~m}(\mathrm{~m} \mathrm{~K})^{-1}\right)$. Materials used in this study are shown in bold font; note that the short double-pivot segment is made from steel.

\begin{tabular}{lrrr}
\hline Material & $\beta$ & $\varepsilon_{\mathrm{AP}}$ & $\varepsilon_{\mathrm{TA}}$ \\
\hline Plastic (ABS, PVC) & 80 & $\pm 3.74 \mathrm{~mm}$ & $\pm 1.69 \mathrm{~mm}$ \\
Aluminum & 22 & $\pm 1.03 \mathrm{~mm}$ & $\pm 0.46 \mathrm{~mm}$ \\
Steel & 12 & $\pm \mathbf{0 . 5 6} \mathrm{mm}$ & $\pm 0.25 \mathrm{~mm}$ \\
Wood, along grain & 3 & $\pm 0.14 \mathrm{~mm}$ & $\pm \mathbf{0 . 0 6} \mathrm{mm}$ \\
\hline
\end{tabular}

tested in a Caron 7900-25 freeze-thaw chamber at an inclination of $0^{\circ}$ while changing temperature from 20 to 0 to $-20^{\circ} \mathrm{C}$ with $3 \mathrm{~h}$ at each temperature and $2 \mathrm{~h}$ for transitions. Temperature was monitored using GeoPrecision M-Log5W-SIMPLEUS miniature data loggers with a precision of $0.01{ }^{\circ} \mathrm{C}$ and an accuracy of $\pm 0.1^{\circ} \mathrm{C}$. Inclination is converted to an equivalent elevation difference $\mathrm{d} Y=\sin (\alpha) \times 1.5 \mathrm{~m}$ for easy comparison with the field installation (Fig. 4). The stability of inclination between -20 and $20^{\circ} \mathrm{C}$, after few hours of equilibration, was within $\pm 0.8 \mathrm{~mm}$. In the presence of strong temperature gradients $\left(\approx 10^{\circ} \mathrm{Ch}^{-1}\right)$, differences up to $\pm 2.5 \mathrm{~mm}$ were observed. The four tilt loggers tested showed no uniform response in their error. By comparison, the manufacturer states a repeatability equivalent to $\mathrm{d} Y=0.045 \mathrm{~mm}$; whether this includes the effect of variable temperature and temperature gradients is unknown. As the laboratory testing is not based on an inclination reference with known accuracy, there is a possibility that the higher temperature-related error reported here is an artifact of the freeze-thaw chamber deforming during temperature cycles. For the current work, these tests at least highlight the importance of temporal temperature gradients in affecting tilt measurements, and they provide a conservative (high) estimate of the error introduced.

\subsection{Data processing}

Hourly data are read from the original logger files and converted to elevation differences relative to 15 September 2017. Hourly soil temperatures, recorded by a separate instrument, are interpolated linearly to the times logged by the tilt meters at each location. Hourly data are aggregated to daily values using the arithmetic mean of soil temperature. For elevation differences the median is used as it is more tolerant to extreme values caused by fast heating and cooling. Diurnal ranges of surface elevation and logger temperature are derived based on the daily minimum and maximum values after detrending the original time series with a centered $25 \mathrm{~h}$ running mean.

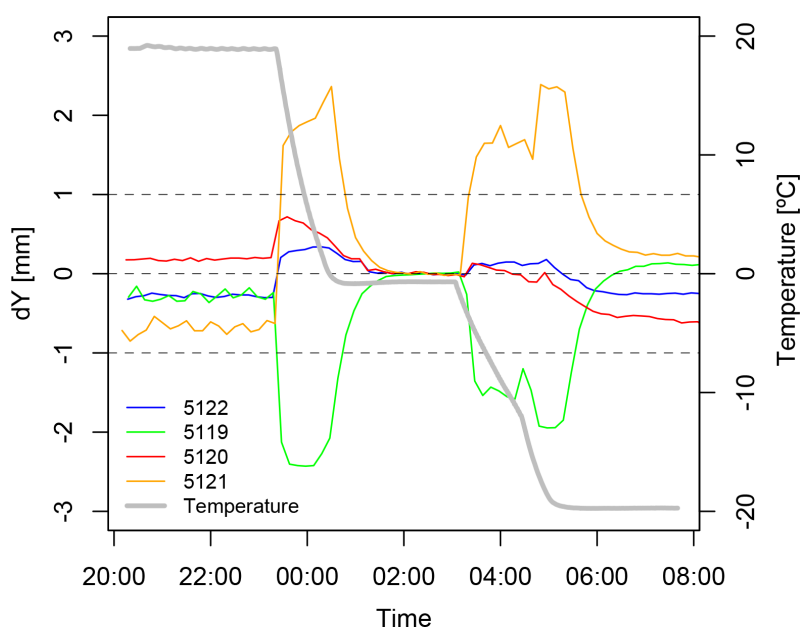

Figure 4. Tilt measured by differing sensors in the laboratory. The instruments, identified by their serial numbers, have not been moved during the experiment; instrument 5119 is not used in the field. Inclination is expressed as equivalent elevation change $\mathrm{d} Y$ assuming an arm of length $1.5 \mathrm{~m}$ as is used in the field.

\subsection{Estimating vertical movement from surface temperature time series based on the Stefan equation}

Under the assumptions of saturated conditions, negligible amounts of liquid water in frozen soil and no water movement, the progressive top-down thawing of soil can be related to an equivalent subsidence $s=z \phi\left(1-\left(\rho_{\mathrm{i}} / \rho_{\mathrm{w}}\right)\right)$, where $z$ is the thickness of soil thawed, $\phi$ is the porosity of the soil, and $\rho_{\mathrm{i}}$ and $\rho_{\mathrm{w}}$ are the densities of ice and water.

The Stefan equation relates the evolution of surface temperature to the progression of the freezing or thawing front in the soil. When the absolute depth of freezing or thawing is required, terms accounting for the thermal conductivity of the soil between the surface and the frozen/unfrozen interface and for the volumetric latent heat of the soil undergoing phase change as well as correction factors to account for the heat capacity of soil exist (Kurylyk and Hayashi, 2016). Here, only the shape of the temporal progression of subsidence or heave $z \propto \sqrt{I(t)}$ is used, where $I(t)$ is the thawing index as derived from the cumulative summation of daily positive temperatures or the freezing index based on negative temperatures.

Freezing indices $\left({ }^{\circ} \mathrm{Cd}\right)$ for each winter were derived from the sum of negative daily soil temperatures during nine months after 1 September and thawing indices for summer from positive daily temperatures in nine months after 1 March. The start and end days of the freezing and thawing seasons are found by using the minimum and maximum of each series, excluding values of zero. For display as time series, indices are scaled to coincide with the observed surface elevation on those dates. 


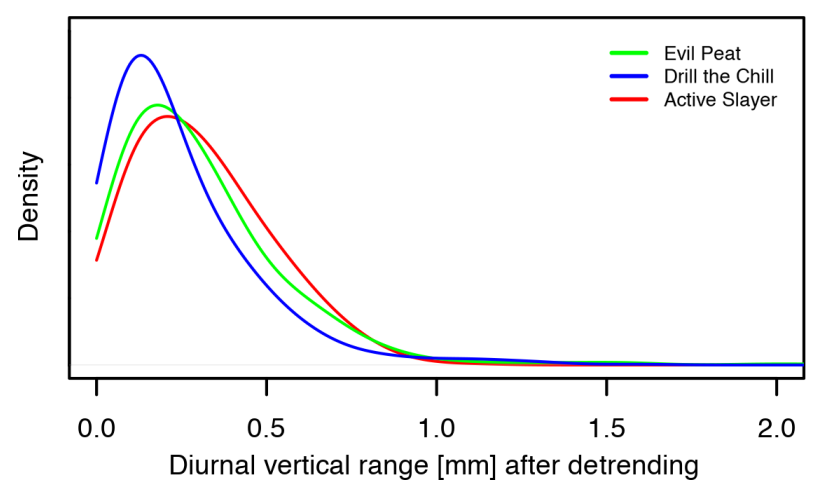

Figure 5. Probability density of diurnal vertical movement for all three sites. The height of the curves indicates the relative frequency of occurrence of intervals of diurnal vertical movement, for example those smaller versus larger than $1 \mathrm{~mm}$.

\section{Results and interpretation}

\subsection{Diurnal movement}

The diurnal range of movement is almost always less than $1 \mathrm{~mm}$ (Fig. 5), and the diurnal temperature range in the tilt loggers is mostly less than $30^{\circ} \mathrm{C}$. A significant fraction of the diurnal oscillation is likely an artifact, related to thermally conditioned changes of installation geometry and measurement electronics. This is in line with the error estimates presented in Sect. 4.4 and 4.5, and as a consequence, diurnal patterns are not interpreted here.

\subsection{Detailed time series}

The detailed movement and relevant auxiliary information are displayed in Fig. 6. Here, the prominent features identified in the figure are described, and for some, hypotheses on their drivers and determinants are formulated. Approximate near-surface zero-curtain periods, the duration of ground freezing and snowpack ripening are inferred visually.

At Active Slayer, a short period of increasing heave is offset partially by subsidence (A) before relative stability for the rest of the first winter. In the second winter, there is a similar initial period of heave (B), followed by long stability. In contrast to the previous year, there is no subsidence after the initial heave and the overall amount of heave is about 3 times larger. The start of both periods of stability is synchronous with the establishment of a thick snow cover (Yellowknife airport), although this may be coincidental. During summer, subsidence resembles the shape expected based on the Stefan equation but is interrupted by a period of stability (C), and a similar effect may be visible near the end of the time series. This effect may be related to the vertical distribution of ice in the soil, with a desiccated zone, which does not consolidate upon thaw, at intermediate depth in the active layer.

At Drill the Chill, a period of heave exists after snowpack ripening during the first winter (D). It is followed by the onset of subsidence, while near-surface ground temperature remains isothermal. This pattern may derive from the refreezing of snowmelt infiltrating into frozen soil and subsequent progressive thaw that has not yet reached the depth of the temperature sensor. An initial phase of heave (E), followed by minor subsidence, is prominent in the first winter and detectable in the second. While reminiscent of feature A, all three instances differ in shape, magnitude and duration. Toward the end of the second winter, a period of relatively steady heave and a total magnitude of about $15 \mathrm{~mm}$ (F) exists. While features D and F may be interpreted as phase changes near the bottom of the active layer, where saturated conditions are frequently found and freezing would commence only late in winter, the relatively rapid rate of heave contrasts with the slow progression of freezing and heave to be expected late in winter based on the Stefan equation.

Sudden heave followed by gradual subsidence is identified by G, and these features are abundant both at Drill the Chill and at Evil Peat. For a subset of features, thin blue dotted lines highlight the synchronicity of heave between sites and with heavy precipitation recorded at the Yellowknife airport. This synchronicity and the resemblance of the subsidence phase and recession curves support an attribution to hydrologic drivers. As such, also less obvious features observed need to be considered as possibly related to the water balance, including lateral flow. This may offer an explanation for the anomalous thaw season at Evil Peat, where net heave instead of subsidence was observed in summer $2018(\mathrm{H})$ in contrast to the partial summer of 2017 (I). Finally, Drill the Chill and Evil Peat have a synchronous episode resembling a dip (J). Here, subsidence may coincide with the onset of thaw and heave with the infiltration and refreezing of early spring precipitation.

\subsection{Comparison with Stefan equation}

The observed elevation change deviates from estimates using the Stefan equation. Figure 7 shows observed elevation change and scaled predictions, shifted to coincide with observations at the start and end of the freezing and thawing seasons. First, the general seasonal evolution of observation and model differ in most cases, and in one season, prediction and observation have opposite signs. Second, some observed features of heave and subsidence last several days to several weeks and cannot correspond to the monotonous progression described by the Stefan equation. It is therefore likely, and illustrated well by Fig. 6, that processes other than volume changes due to the advance of freezing and thawing have additional, and possibly dominating, influence on the observed patterns. 


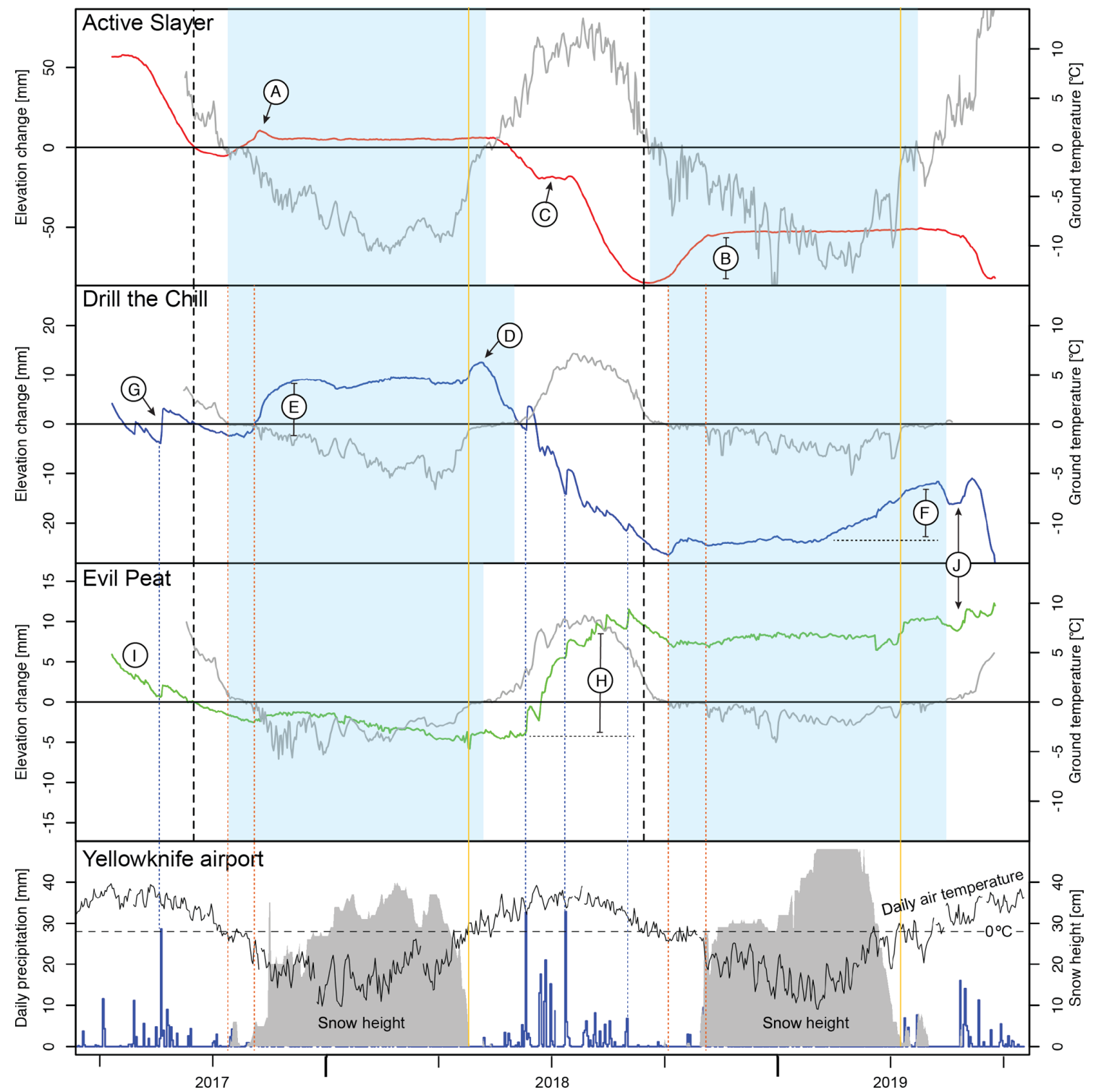

Figure 6. Daily elevation change and ground temperature $(0.30-0.35 \mathrm{~mm})$ recorded at the three sites, with nearby $(<25 \mathrm{~km})$ precipitation (blue steps) and snow height (grey polygons). Air temperature (black) is shown relative to $0{ }^{\circ} \mathrm{C}$ (dashed) for context and without scale. Blue shading indicates approximate period of soil freezing; orange vertical lines indicate the approximate timing of snowpack ripening and meltwater input into the ground; and vertical dashed lines indicate 1 full measurement year (black), selected precipitation events (blue), and the approximate duration of the autumn zero-curtain periods at Drill the Chill and Evil Peat (red). Letters in circles identify events discussed in the main text.

\section{Discussion}

\subsection{Findings in relation with previous work}

The changes in surface elevation between both winters range from $10 \mathrm{~mm}$ heave to $60 \mathrm{~mm}$ subsidence, similar to interannual changes reported from other studies based on continuous (Overduin and Kane, 2006) and annual (e.g., O’Neill et al., 2019) observations in permafrost areas. Similarly, the seasonal amplitudes of $15-60 \mathrm{~mm}$ are within the range of 20 $120 \mathrm{~mm}$ commonly reported for other sometimes vegetation- free and seasonally frozen areas (e.g., Matsuoka, 1994; Hallet, 1998). By contrast, the diurnal range of heave reported previously is much larger than the present study, for example 10-40 mm (Matsuoka et al., 1997). This is likely because those studies focused on frost heave in bare soil, which has temperature cycles that are much less dampened than at the sites reported here.

An early-winter peak in heave followed by brief subsidence during early winter, similar to feature (A) in Fig. 6, was previously detected at a seasonally frozen and near- 


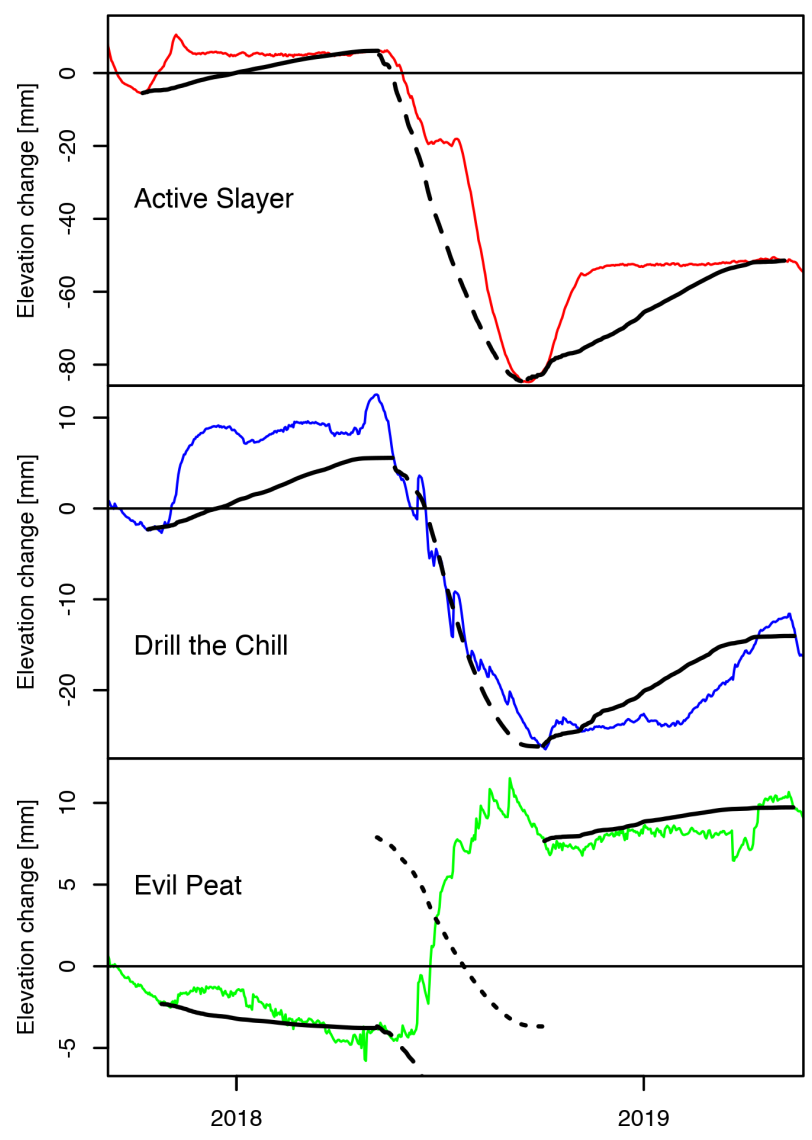

Figure 7. Visual comparison of observed elevation change (color) with predictions (black) based on the Stefan equation and ground temperature. Solid black lines represent freezing seasons and dashed lines thawing seasons. The dotted line for site Evil Peat has been shifted upwards for clarity, illustrating that the observed thawing season was accompanied by surface heave, whereas the Stefan model predicts subsidence. Predictions are scaled and shifted to coincide with observations at the start and end of the freezing and thawing seasons and, therefore, can only be used to visually assess how well they resemble the temporal pattern of elevation but not seasonal magnitude.

horizontal site (Matsuoka, 1994) but not interpreted. At other seasonally frozen sites (Matsuoka et al., 1997; Matsuoka, 2003; Matsumoto et al., 2010) and one in permafrost (Hallet, 1998); however, winters showed gradual early heave, without an early-winter peak. These previously studied sites had frost-susceptible fines like Active Slayer but negligible vegetation or organic cover.

Late-winter heave followed by thawing and subsidence similar to (D) and possibly (F) in Fig. 6 has been reported previously (e.g., Matsumoto et al., 2010) and, because of its association with the zero-curtain period, also hypothesized to be caused by infiltration and refreezing of water in permeable frozen ground (Matsuoka et al., 1997; Matsuoka, 2003) or by ice segregation at shallow depths following initiation of surface thaw (Harris et al., 2008).
A late-winter dip, similar to feature (J) at Drill the Chill and Evil Peat, was observed previously at sloping and seasonally frozen sites (Matsuoka, 1994; Harris et al., 2008) but was not interpreted. These sites had frost-susceptible fines, whereas the observations of $(\mathbf{J})$ were made on organic material at least $1 \mathrm{~m}$ thick. Hydrologic control on elevation change, as hypothesized for $(\mathrm{G})$ and $(\mathrm{H})$, has been described for peat on scales from hours to years (cf. Price and Schlotzhauer, 1999).

\subsection{Differing environments and applications}

The vertical movement of the soil surface is, to various degrees, determined by climate, the characteristics and stratigraphy of ground materials, hydrology, and possibly vegetation. The study presented here samples three sites in warm, and likely thawing, permafrost. Many of the interesting geocryological phenomena, including summer heave (Mackay, 1983), the growth of segregated near-surface ground ice (O'Neill and Burn, 2012), the formation of injection ice (Morse and Burn, 2014), or differential heave and settlement in patterned ground, including experimental site manipulation (Kokelj et al., 2007), may be studied with tilt arms at other locations. Similarly, phenomena of seasonal freezing (e.g., Harris et al., 2008) may be investigated.

As permafrost areas progressively enter a state of pervasive thaw and ground-ice loss, quantifying and understanding surface subsidence and heave becomes increasingly important. While episodic measurements may reveal multiannual trends, it will likely be high-resolution observations that can drive progress in simulation of subsidence and the interpretation of remote sensing data. This method and the results of this study may be relevant for other applications such as correcting snow-height observations for the heave and subsidence beneath the snow pack, monitoring peatland hydrology and seasonal frost heave in nonpermafrost areas, or providing ground truth for remote sensing studies. The trend of decreasing cost for tilt sensors and data logging systems is expected to continue and will make the wide replication of this method increasingly affordable.

\subsection{Improving the tilt-arm setup}

Wood has been chosen as the material for the tilt arm due to its low coefficient of thermal expansion. However, deterioration of the varnish and ingress of moisture over time may lead to longitudinal expansion of up to $0.4 \%$ (Hann, 1969), equivalent to an additional elevation error of $\pm 0.2 \mathrm{~mm}$, and also an unknown amount of warping may occur. As a consequence, steel pipe is the preferable material for future tilt arms.

The anchor pipes in this experiment are relatively shallow, and long-term installations will benefit from deep anchoring because the possibility of upward vertical displacement (frost jacking) has to be taken into account. This is because anchor 
pipes embedded insufficiently deep in permafrost may not have the resistance to counteract heaving forces developed in the active layer (cf. Ladanyi and Foriero, 1998). The establishment of additional nearby benchmarks, in bedrock or with other pipes, is useful to support the regular surveying of the tilt-arm installation. Periodic surveying will allow one to ascertain the integrity of long time series by demonstrating no frost jacking or lowering of the pipe due to thaw have occurred. Given the absence of experience with miniaturized tilt loggers operating in cold environments in the long term, measuring tilt-arm inclination with a manual inclinometer or digital level during field visits is advisable as it will permit one to detect if significant sensor drift should occur over time.

Lateral movement of the soil can occur on sloping surfaces (e.g., Harris et al., 2007) or be caused by lateral heterogeneity (e.g., Kokelj et al., 2007; Kääb et al., 2014). Where lateral movement occurs, tilt-arm installations may need to be serviced episodically to maintain a favorable geometry. Where lateral heterogeneity of materials and ground conditions is large, e.g. in hummocky terrain or in forest, multiple arms may be needed to adequately represent one terrain type, and, additionally, the lateral tilt of shallow stakes may reveal growth or collapse of hummocks. Similarly, an instrument resembling a heave meter (e.g., Mackay et al., 1979) can be composed of multiple tilt arms to measure differential frost heave. Finally, given that an influence of water-table fluctuations was inferred, the direct measurement of water level at tilt-arm installations may prove to be valuable.

\section{Conclusions}

This study demonstrates a simple method for obtaining highresolution time series of surface elevation change and, based on analysis of the data obtained, supports these conclusions:

1. The tilt-arm setup can efficiently monitor surface heave and subsidence over time. The accuracy of daily median values, conservatively expressed as the maximum error expected from the effects of thermal expansion and sensor stability over the entire measurement period, is $\pm 1.4 \mathrm{~mm}$. Hourly values are subject to additional variation of $\pm 0.5 \mathrm{~mm}$ that is largely an artifact from strong thermal gradients.

2. The observed seasonal patterns differ strongly from the prediction of a simple Stefan model and observed nearsurface ground temperature. Consequentially, processes other than surface-driven phase change in homogeneous soil are important for explaining surface movement.

3. High-resolution surface heave and subsidence data reveal features that may help to elucidate underlying processes or to discover similarities in space and time. Some of these features have been previously observed but not interpreted in detail.
4. Interannual, seasonal, and subseasonal patterns of subsidence and heave differ in magnitude and sign between the three sites, despite their proximity. This underscores the need to better understand the freeze-thaw processes driving this spatial and temporal heterogeneity. Furthermore, it points to the importance of remote sensing for investigating spatial patterns of terrain subsidence and heave.

5. The interpretation of surface movement as a proxy for freezing and thawing processes can be confounded by hydrologic effects.

Code and data availability. Field data, including $\mathrm{R}$ code to generate the plots, are available from https://doi.org/10.5281/zenodo.3466097 (Gruber, 2019).

Competing interests. The author is affiliated with Cryogeeks Ltd, a company that sells the GeoPrecision products mentioned in this article and develops competing products for the tilt loggers described here.

Acknowledgements. Thomas Knecht performed the laboratory tests. During the field campaign, Emilie Stewart-Jones, Ariane Castagner, Thomas Knecht and Stuart MacDonald helped with drilling and installation of instruments; Rupesh Subedi, Christian Peart and Nick Brown installed some of the temperature monitoring sites used here. The Northwest Territories Geological Survey supported field logistics, and Steve Kokelj gave advice on site selection. Bill Leard built the tilt arms and insisted rightfully that they must have the double pivot. Thank you to Bin Cao, Jayson Eppler and Steve Kokelj for their comments on the manuscript. Two anonymous referees and the editor supported the quality of this paper with their comments.

Financial support. This research has been supported by the Natural Sciences and Engineering Research Council of Canada (grant no. RGPIN-2015-06456). Equipment was available via the project "Quantifying the Hidden Thaw" supported by the Canada Foundation for Innovation and the Ontario Research Fund. NSERC PermafrostNet provided additional support.

Review statement. This paper was edited by Ylva Sjöberg and reviewed by two anonymous referees.

\section{References}

Anonymous: Mass-balance terms, J. Glaciol., 8, 3-7, 1969.

Arenson, L. U., Kääb, A., and O'Sullivan, A.: Detection and analysis of ground deformation in permafrost environments, Permafrost Periglac., 27, 339-351, https://doi.org/10.1002/ppp.1932, 2016. 
Bartsch, A., Leibman, M., Strozzi, T., Khomutov, A., Widhalm, B., Babkina, E., Mullanurov, D., Ermokhina, K., Kroisleitner, C., and Bergstedt, H.: Seasonal progression of ground displacement identified with satellite radar interferometry and the impact of unusually warm conditions on permafrost at the Yamal Peninsula in 2016, Remote Sensing, 11, 1865, https://doi.org/10.3390/rs11161865, 2019.

Fahey, B. D.: Seasonal frost heave and frost penetration measurements in the indian peaks region of the Colorado Front Range, Arctic Alpine Res., 6, 63-70, https://doi.org/10.2307/1550370, 1974.

Government of Canada: Yellowknife A, daily data reports, available at: http://climate.weather.gc.ca/climate_data/daily_data_e.html? StationID=51058 (last access: 21 July 2019), 2019.

Gruber, S.: Data and code to accompany the manuscript "Ground subsidence and heave over permafrost: hourly time series reveal inter-annual, seasonal and shorter-term movement caused by freezing, thawing and water movement" (Version initial), Data set, Zenodo, https://doi.org/10.5281/zenodo.3466097, 2019.

Hallet, B.: Measurement of soil motion in sorted circles, Western Spitsbergen, in: Proceedings ofthe Seventh International Conference on Permafrost, Centre d'études Nordiques, Université Laval, Québec, 55, 415-420, 1998.

Hann, R. A.: Longitudinal shrinkage in seven species of wood, Tech. Rep. FPL-0203, Forest Products Laboratory (FPL) USDA, 1969.

Harris, C., Luetschg, M., Davies, M. C. R., Smith, F., Christiansen, H. H., and Is aksen, K.: Field instrumentation for real-time monitoring of periglacial solifluction, Permafrost Periglac., 18, 105114, https://doi.org/10.1002/ppp.573, 2007.

Harris, C., Kern-Luetschg, M., Smith, F., and Isaksen, K.: Solifluction processes in an area of seasonal ground freezing, Dovrefjell, Norway, Permafrost Periglac., 19, 31-47, https://doi.org/10.1002/ppp.609, 2008.

Hasler, A., Gruber, S., and Beutel, J.: Kinematics of steep bedrock permafrost, J. Geophys. Res., 117, F01016, https://doi.org/10.1029/2011JF001981, 2012.

Heginbottom, J.: Some effects of surface disturbance on the permafrost active layer at Inuvik, N.W.T., in: North American contribution: permafrost, second international conference, National Academy of Science, Washington, DC, 649-657, https://doi.org/10.1192/bjp.112.483.211-a, 1973.

Hwang, C. T.: Predictions and observations on the behaviour of a warm gas pipeline on permafrost, Can. Geotech. J., 13, 452-480, https://doi.org/10.1139/t76-045, 1976.

Kääb, A., Girod, L., and Berthling, I.: Surface kinematics of periglacial sorted circles using structure-from-motion technology, The Cryosphere, 8, 1041-1056, https://doi.org/10.5194/tc8-1041-2014, 2014.

Kokelj, S. V., Burn, C. R., and Tarnocai, C.: The structure and dynamics of earth hummocks in the subarctic forest near Inuvik, Northwest Territories, Canada, Arct. Antarct. Alp. Res., 39, 99-109, https://doi.org/10.1657/15230430(2007)39[99:TSADOE]2.0.CO;2, 2007.

Kurylyk, B. L. and Hayashi, M.: Improved Stefan equation correction factors to accommodate sensible heat storage during soil freezing or thawing, Permafrost Periglac., 27, 189-203, https://doi.org/10.1002/ppp.1865, 2016.
Ladanyi, B. and Foriero, A.: Evolution of frost heaving stresses acting on a pile, in: Proceedings of Seventh International Conference Permafrost, Collection Nordicana, Yellowknife, 55, 623633, 1998.

Lambiel, C. and Delaloye, R.: Contribution of real-time kinematic GPS in the study of creeping mountain permafrost: examples from the Western Swiss Alps, Permafrost Periglac., 15, 229-241, https://doi.org/10.1002/ppp.496, 2004.

Lee, H., Swenson, S. C., Slater, A. G., and Lawrence, D. M.: Effects of excess ground ice on projections of permafrost in a warming climate, Environ. Res. Lett., 9, 124006, https://doi.org/10.1088/1748-9326/9/12/124006, 2014.

Little, J. D., Sandall, H., Walegur, M. T., and Nelson, F. E.: Application of differential global positioning systems to monitor frost heave and thaw settlement in tundra environments, Permafrost Periglac., 14, 349-357, https://doi.org/10.1002/ppp.466, 2003.

Liu, L., Zhang, T., and Wahr, J.: InSAR measurements of surface deformation over permafrost on the North Slope of Alaska, J. Geophys. Res., 115, F03023, https://doi.org/10.1029/2009JF001547, 2010.

Mackay, J. R.: Disturbances to the tundra and forest tundra environment of the western Arctic, Can. Geotech. J., 7, 420-432, https://doi.org/10.1139/t70-054, 1970.

Mackay, J. R.: The growth of pingos, Western Arctic coast, Canada, Can. J. Earth Sci., 10, 979-1004, https://doi.org/10.1139/e73086, 1973.

Mackay, J. R.: Downward water movement into frozen ground, western arctic coast, Canada, Can. J. Earth Sci., 20, 120-134, https://doi.org/10.1139/e83-012, 1983.

Mackay, J. R., Ostrick, J., Lewis, C. P., and Mackay, D. K.: Frost heave at ground temperatures below zero degrees centigrade, Inuvik, Northwest Territories, Tech. rep., https://doi.org/10.4095/104879, 1979.

Matsumoto, H., Yamada, S., and Hirakawa, K.: Relationship between ground ice and solifluction: Field measurements in the Daisetsu Mountains, northern Japan, Permafrost Periglac., 21, 78-89, https://doi.org/10.1002/ppp.675, 2010.

Matsuoka, N.: Continuous recording of frost heave and creep on a Japanese alpine slope, Arctic Alpine Res., 26, 245-254, 1994.

Matsuoka, N.: Contemporary permafrost and periglaciation in Asian high mountains: an overview, Z. Geomorphol., 47, 145166, 2003.

Matsuoka, N., Hirakawa, K., Watanabe, T., and Moriwaki, K.: Monitoring of periglacial slope processes in the Swiss Alps: the first two years of frost shattering, heave and creep, Permafrost Periglac., $\quad 8, \quad 155-177$, https://doi.org/10.1002/(SICI)10991530(199732)8:2<155::AID-PPP248>3.0.CO;2-N, 1997.

Matthews, B.: Automatic measurement of frost-heave: results from Malham and Rodley (Yorkshire), Geoderma, 1, 107-115, 1967.

Morse, P. D. and Burn, C. R.: Perennial frost blisters of the outer Mackenzie Delta, western Arctic coast, Canada, Earth Surf. Proc. Land., 39, 200-213, https://doi.org/10.1002/esp.3439, 2014.

Morse, P. D., Wolfe, S. A., Kokelj, S. V., and Gaanderse, A. J.: The occurrence and thermal disequilibrium state of permafrost in forest ecotopes of the Great Slave Region, Northwest Territories, Canada, Permafrost Periglac., 27, 145-162, https://doi.org/10.1002/ppp.1858, 2016.

Nixon, F. M. and Taylor, A. E.: Regional active layer monitoring across the sporadic, discontinuous and continuous permafrost 
zones, Mackenzie Valley, northwestern Canada, Proceedings of the Seventh International Conference on Permafrost, 815-820, 1998.

Nixon, F. M., Taylor, A. E., Allen, V. S., and Wright, F.: Active layer monitoring in natural environments, lower Mackenzie Valley, Northwest Territories, in: Current Research 1995-B, 99-108, 1995.

Nixon, J. F., Morgenstern, N. R., and Nixon, J. F.: One-dimensional consolidation of thawing soils, Can. Geotech. J., 8, 558-565, https://doi.org/10.1139/t71-057, 1971.

O'Neill, H. B. and Burn, C.: Physical and temporal factors controlling the development of near-surface ground ice at Illisarvik, western Arctic coast, Canada, Can. J. Earth Sci., 49, 1096-1110, https://doi.org/10.1139/e2012-043, 2012.

O’Neill, H. B., Smith, S. L., and Duchesne, C.: Longterm permafrost degradation and thermokarst subsidence in the Mackenzie Delta area indicated by thaw tube measurements, in: Cold Regions Engineering 2019, American Society of Civil Engineers, Reston, VA, 1, 643-651, https://doi.org/10.1061/9780784482599.074, 2019.

Outcalt, S. I.: An algorithm for needle ice growth, Water Resour. Res., 7, 394-400, https://doi.org/10.1029/WR007i002p00394, 1971.

Overduin, P. P. and Kane, D. L.: Frost boils and soil ice content: field observations, Permafrost Periglac., 17, 291-307, https://doi.org/10.1002/ppp.567, 2006.

Price, J. S. and Schlotzhauer, S. M.: Importance of shrinkage and compression in determining water storage changes in peat: the case of a mined peatland, Hydrol. Proc., 13, 2591-2601, https://doi.org/10.1002/(SICI)10991085(199911)13:16<2591::AID-HYP933>3.0.CO;2-E, 1999.

Rempel, A. W., Wettlaufer, J. S., and Worster, M. G.: Premelting dynamics in a continuum model of frost heave, J. Fluid Mech., 498, 227-244, https://doi.org/10.1017/S0022112003006761, 2004.

Shumskiy, P. A. and Vtyurin, B. I.: Underground ice, in: International Permafrost Conference, 108-113, 1963.

Shur, Y., Hinkel, K. M., and Nelson, F. E.: The transient layer: implications for geocryology and climate-change science, Permafrost Periglac., 16, 5-17, https://doi.org/10.1002/ppp.518, 2005.
Smith, D. J.: Frost-heave activity in the Mount Rae area, Canadian Rocky Mountains, Arctic Alpine Res., 19, 155-166, 1987.

Smith, M. W.: Observations of soil freezing and frost heave at Inuvik, Northwest Territories, Canada, Can. J. Earth Sci., 22, 283 290, https://doi.org/10.1139/e85-024, 1985.

Streletskiy, D. A., Shiklomanov, N. I., Little, J. D., Nelson, F. E., Brown, J., Nyland, K. E., and Klene, A. E.: Thaw subsidence in undisturbed tundra landscapes, Barrow, Alaska, 1962-2015, Permafrost Periglac., 28, 566-572, https://doi.org/10.1002/ppp.1918, 2017.

Weber, S., Fäh, D., Beutel, J., Faillettaz, J., Gruber, S., and Vieli, A.: Ambient seismic vibrations in steep bedrock permafrost used to infer variations of ice-fill in fractures, Earth Planet. Sc. Lett., 501, 119-127, https://doi.org/10.1016/j.eps1.2018.08.042, 2018.

Weber, S., Beutel, J., Da Forno, R., Geiger, A., Gruber, S., Gsell, T., Hasler, A., Keller, M., Lim, R., Limpach, P., Meyer, M., Talzi, I., Thiele, L., Tschudin, C., Vieli, A., Vonder Mühll, D., and Yücel, M.: A decade of detailed observations (20082018) in steep bedrock permafrost at the Matterhorn Hörnligrat (Zermatt, CH), Earth Syst. Sci. Data, 11, 1203-1237, https://doi.org/10.5194/essd-11-1203-2019, 2019.

Wirz, V., Beutel, J., Gruber, S., Gubler, S., and Purves, R. S.: Estimating velocity from noisy GPS data for investigating the temporal variability of slope movements, Nat. Hazards Earth Syst. Sci., 14, 2503-2520, https://doi.org/10.5194/nhess14-2503-2014, 2014.

Wirz, V., Geertsema, M., Gruber, S., and Purves, R. S.: Temporal variability of diverse mountain permafrost slope movements derived from multi-year daily GPS data, Mattertal, Switzerland, Landslides, 13, 67-83, https://doi.org/10.1007/s10346014-0544-3, 2016a.

Wirz, V., Gruber, S., Purves, R. S., Beutel, J., Gärtner-Roer, I., Gubler, S., and Vieli, A.: Short-term velocity variations at three rock glaciers and their relationship with meteorological conditions, Earth Surf. Dynam., 4, 103-123, https://doi.org/10.5194/esurf-4-103-2016, 2016b. 